\title{
Market Design: Harnessing Market Methods to Improve Resource Allocation ${ }^{1}$
}

\author{
Peter Cramton ${ }^{2}$ \\ 15 October 2010
}

\begin{abstract}
The emerging field of market design applies auctions and matching to solve resource allocation problems. This paper focuses on auction design, the branch of market design where money is used to facilitate the exchange of goods and services. Within auctions, the paper examines applications involving government regulated resources. Who should use the scarce radio spectrum and at what prices? How should electricity markets be organized? How should financial markets be regulated? And how should runway access be assigned at congested airports? All of these are important questions in major industries. Researchers in market design have made substantial progress in answering these questions over the last fifteen years. The efforts, although at the forefront of theory have been closely tied to practice, and involved interdisciplinary teams of economists, computer scientists, and engineers, all working to solve real problems. Despite this rapid progress, the field holds much promise to provide better answers in even more complex economic environments over the next two decades. The rewards to society from improved markets will be immense.
\end{abstract}

As deficits grow and baby-boomers age, governments face increasing challenges in making the best use of public resources. One successful innovation to improve the allocation of scarce public resources is for the government to harness market methods to improve decision making. The spectrum auctions, conducted by the Federal Communications Commission (FCC) since 1994, are an excellent example. These auctions, which arose from a collaboration of scientists with auction expertise, industry, and the FCC, have led to over $\$ 100$ billion in new non-distortionary U.S. government revenue, and more importantly, have put the scarce spectrum resource into the hands of those best able to use it. This innovation has been a win-win for taxpayers, the companies participating in the auctions, and the hundreds of millions now enjoying advanced wireless communications services. The auction program has been replicated worldwide and remains a key example of effective government, both in the U.S. and abroad (Milgrom 2004).

The spectrum auction program stimulated key scientific innovations in our understanding of how to auction many related items. These innovations have been applied not just to spectrum auctions but to e-commerce, both public and private. The advances to date, while important, are only the tip of the iceberg. Tremendous opportunities lie ahead and will be realized in coming decades with further scientific advancement in auction design.

Auction applications are rapidly expanding. Communication and computational advances have certainly played an important role, but the development of simple and powerful auction methods has been important too. Market designers now have a much richer set of tools to address more complex problems.

\footnotetext{
${ }^{1}$ This work is licensed under the Creative Commons Attribution-NoDerivs 3.0 Unported License. To view a copy of this license, visit http://creativecommons.org/licenses/by-nd/3.0/ or send a letter to Creative Commons, 171 Second Street, Suite 300, San Francisco, California, 94105, USA.

${ }^{2}$ Professor of Economics, University of Maryland. www.cramton.umd.edu.
} 
One example is a package auction (or combinatorial auction) in which bidders can bid on packages of items (Cramton, et al. 2006). In a package auction bidders can express preferences for complementary items without running the risk that they will win just some of what they need. This is important, for example, in spectrum auctions in which different technologies require that the spectrum be organized in different ways. In the past, the regulator has been forced to decide how the spectrum is organized with a specific band plan-effectively deciding how much spectrum is available for each technology. A package auction enables the regulator to conduct a technology-neutral auction, which lets the bidders determine the band plan through their competitive bids. A good example are recent spectrum auctions in Europe, in which the quantity of paired versus unpaired spectrum is determined in the auction, not by the regulator.

One of the challenges of package auctions is finding an effective way for bidders to convey preferences. There are simply too many packages to ask for preferences for all possible packages. A common approach is to begin with a clock auction. The auctioneer names a price for each product, and bidders respond with their most preferred packages. The price is then raised on all products with excess demand, and the bidding continues. This price-discovery process focuses the bidders' attention on packages that are most relevant. Once this price discovery is over, the bidders are in a much better position to submit any additional bids, as well as improve the bids already submitted. An optimization is then done to determine the value-maximizing assignment, as well as competitive prices that satisfy the stability constraints. Typically, there are many such prices, so a further optimization is done to find the prices that provide the best incentives for truthful bidding.

Package auctions are also proposed for auctioning takeoff and landing rights at congested airports, such as the three New York City airports. The goal of the auction is to make the best use of scarce runway capacity. Left to their own devices, airlines will overschedule flights during peak hours, creating congestion and costly delay. The package auction enables each airline to bid for its preferred package of slots. The resulting competitive prices motivate airlines to substitute away from expensive slots, either by shifting flights to less expensive times or by using larger aircraft to carry the same number of passengers with less runway use.

Another example of market design is electricity markets. Modern electricity markets are organized as a number of auction markets. The markets, taken together, are designed to provide reliable electricity at the least cost to consumers. Spot markets determine how much each supplier is generating on a minute-by-minute basis; forward energy markets enable customers and suppliers to lock in mediumterm prices for electricity; and long-run investment markets coordinate new entry to cover any expansion in electricity demand. These auction markets must be carefully designed to work together to achieve the goal of least costly, reliable supply. Design failures can be quite costly, as the California electricity crisis of 2000-2001 demonstrated. When the stakes are high, an important step in market design is building prototypes and then testing those prototypes in the experimental lab or in the field before full-scale implementation.

Design failures are all too common and persistent in government settings. For example, the Medicare competitive bidding program, which began over ten years ago, is still in a pilot stage and experiencing serious problems, in large part as a result of the implementing agency failing to apply state-of-the-art methods and principles to the problem of how to price Medicare equipment and supplies. Good auction design in complex environments involves more than good intentions -it requires exploiting the substantial advances that we have seen in market design over the last fifteen years. The recent financial crisis is another example where the principles of market design, if effectively harnessed by regulators, could have prevented or at least mitigated the crisis. These failures can involve trillions of dollars of cost to society, and certainly involve many billions. 
One exciting aspect of market design is working on the forefront of theory and bringing that theory to practice. In both auctions and matching, solving real problems has proved to be an excellent way to develop new theory. The applications benefit from the improved markets, and the theory is enriched in the process. The process typically has involved scientists from several disciplines, especially economics, computer science, operations research, and engineering. New and powerful specialties have emerged, such as algorithmic game theory within computer science (Nisan et al. 2007).

Market design is a young and vibrant field. Specialized interdisciplinary conferences are common, even within research organizations that have historically focused on traditional fields. For example, the National Bureau of Economic Research now has an interdisciplinary market design group that meets annually. About one-half of this year's attendees were advanced doctoral students from elite research universities from around the world. Courses in market design are now offered at many leading research universities at both the undergraduate and graduate levels.

Over the last fifteen years, the emerging field of market design has demonstrated the power of harnessing market methods to allocate scarce resources. The process has involved interdisciplinary efforts among economists, computer scientists, and engineers, focused on solving practical problems of resource allocation. The societal gains from these efforts has been substantial in several major industries such as telecommunications, energy, and transportation. The field holds much promise for future advances in both theory and application. Given the close and complementary connection between the science and the practice, these advances will produce substantial and lasting welfare gains to society over the next twenty years.

\section{References}

Cramton, Peter, Yoav Shoham, and Richard Steinberg (2006), Combinatorial Auctions, Cambridge, MA: MIT Press.

Milgrom, Paul (2004), Putting Auction Theory to Work, Cambridge: Cambridge University Press.

Nisan, Noam, Tim Roughgarden, Eva Tardos, and Vijay V. Vazirani (2007), Algorithmic Game Theory, Cambridge: Cambridge University Press. 